\title{
Goodbye Analytical Cellular Pathology, hello Cellular Oncology!
}

This is the last issue of Analytical Cellular Pathology, that brings you the abstracts of the last conference of the European Society for Analytical Cellular Pathology (ESACP) that was held at the VU University in Amsterdam, The Netherlands, from 1-4 October 2003. This meeting (the International Conference on Applied Genomics) was a joint meeting with the International Society for Analytical Cellular Pathology (ISDQP). This joint meeting was the final one in a series of joint meetings between the two Societies, illustrating how close the Societies had grown together over the years. Traditionally, the ESACP had more focus on quantitative biology and technology, but in recent years there has been more interest in clinical applications as was apparent on the various meetings of the Society. The ISDQP had traditionally more focus on applications of quantitative techniques, but had shifted more towards newer technology and biology in recent years. The Societies shared many members, but were both relatively small. After extensive talks between the boards of the two Societies, it became clear that the only way to go forward was to merge the two Societies.

This process has taken several years, during which a draft of the constitution for the new Society was formed, the members of both mother Societies were informed and heard, and ballots were organized to vote on the merger and the constitution draft. During the Amsterdam meeting, this process has come to a close. Had the ISDQP members voted favourably before, the ESACP members accepted the proposals during the Amsterdam meeting. Thereby, the ESACP and ISDQP were closed, and a new society was formed, which will be called the International Society for Cellular Oncology (ISCO). The interim board of ISCO, which is composed of the officers of the mother Societies and which will be in function until proper elections at the next ISCO meeting in Belfast in 2005, believes this name to reflect best what we have done in the past, do now and/or want to do in the years to come: to study cellular processes in cancer. Cancer has been the focus of most activities within both mother Societies anyway, but of course technology will keep us connected with those studying other diseases. ISCO will be able to host all traditional activities of the mother Societies, but will create new opportunities as we will be better visibly to and thereby more attractive for scientists and clinicians working in cancer biology and genomics. Hopefully, this will lead to larger membership of ISCO and bigger meetings.

The new Society deserves a new Journal. The ISQDP had Analytical and Quantitative Cytology and Histology as its (unowned) home journal, and the ESACP owned Analytical Cellular Pathology (ACP). The best solution in the end was to re-launch ACP as "Cellular Oncology", with a new board, a new editor, and new looks. All this is being worked on, and we hope to announce the new editor and the new board soon. Cellular Oncology will have a website where all papers will be electronically available, and will inherit the impact factor from ACP to make sure the new Journal won't have to survive the usual first few difficult years without this important bibliographic measure. Further, we will have to work on an electronic submission and reviewing system. All this will give Cellular Oncology a good chance of success, but naturally it will take the lasting efforts of all of us to invest in our own new Journal with good papers.

Paul J. van Diest, MD, PhD President of the International Society for Cellular Oncology 


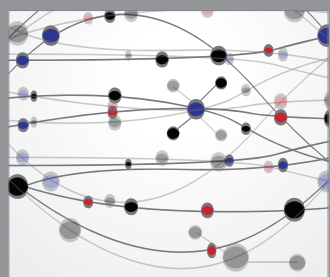

The Scientific World Journal
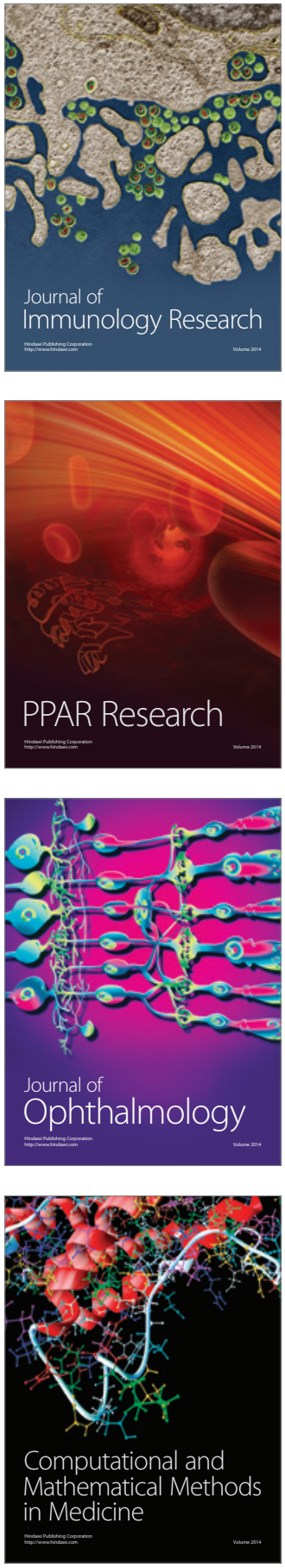

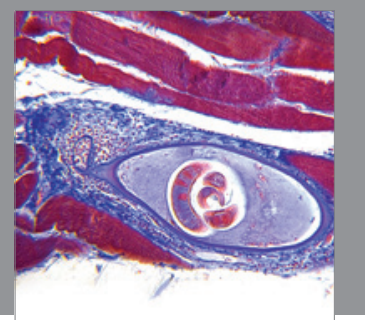

Gastroenterology

Research and Practice
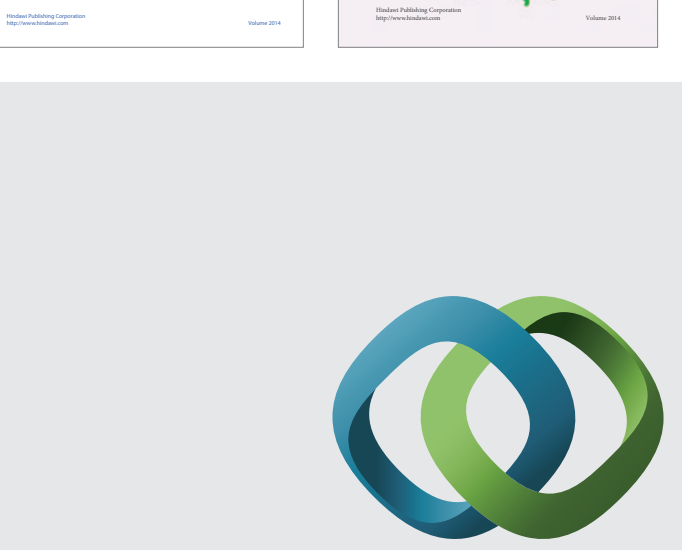

\section{Hindawi}

Submit your manuscripts at

http://www.hindawi.com
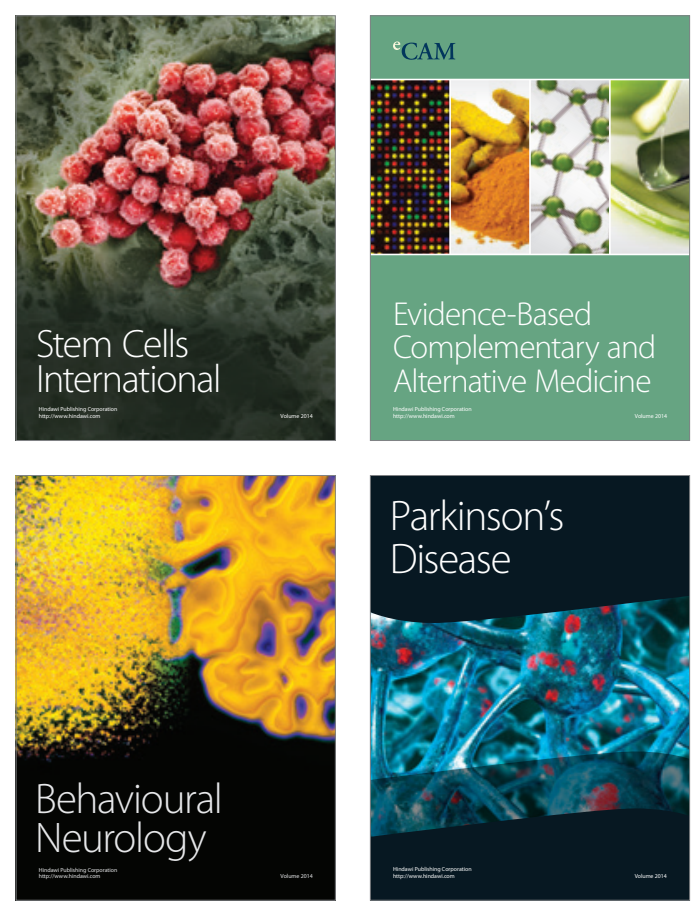

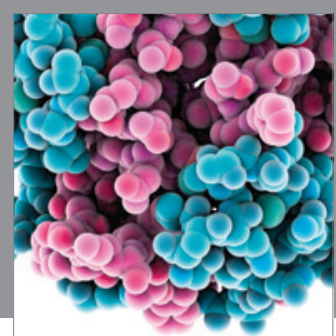

Journal of
Diabetes Research

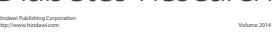

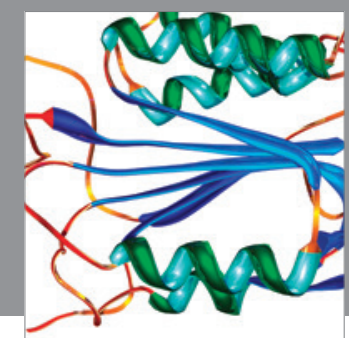

Disease Markers
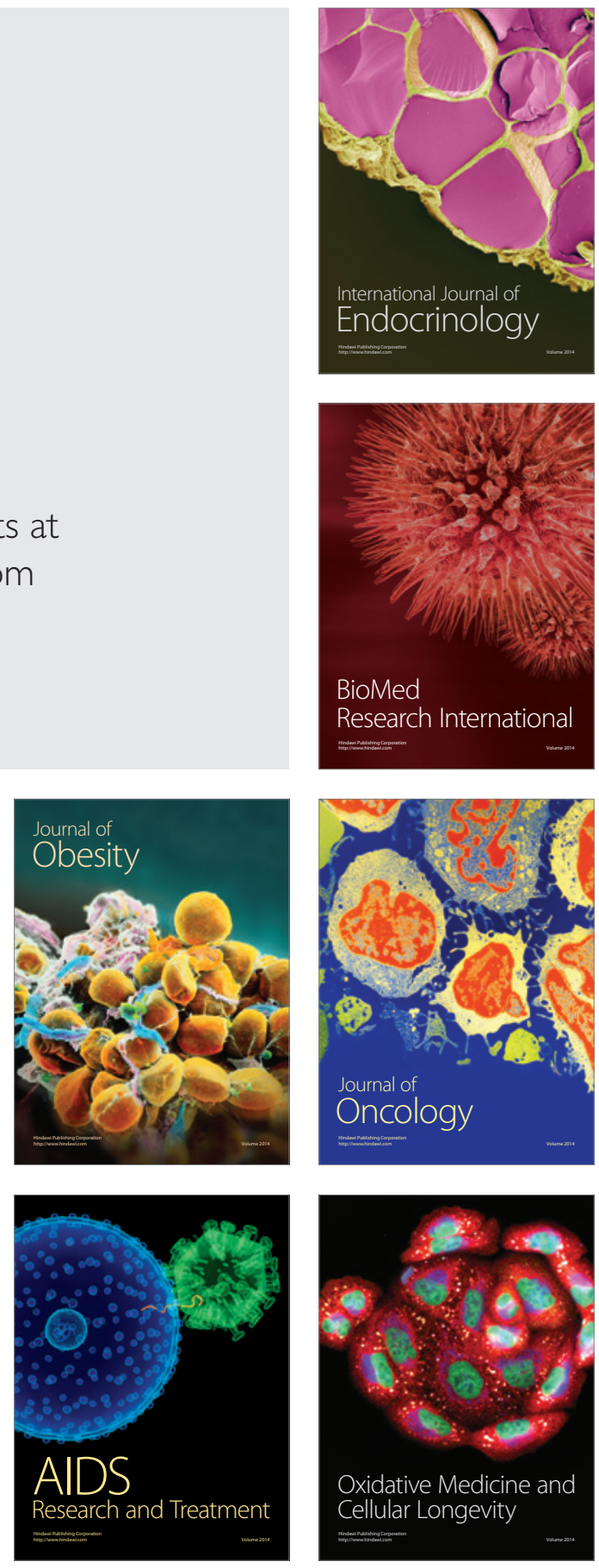